\title{
Thermal Diffusion in Fibrous Aerogel Blankets
}

\author{
Ákos Lakatos 1,*(i) and Anton Trník ${ }^{2,3}$ (i) \\ 1 Department of Building Services and Building Engineering, Faculty of Engineering, University of Debrecen, \\ Ótemető str 2-4 1, 4028 Debrecen, Hungary \\ 2 Department of Physics, Faculty of Natural Sciences, Constantine the Philosopher University in Nitra, Tr. A \\ Hlinku 1, 94974 Nitra, Slovakia; atrnik@ukf.sk \\ 3 Department of Materials Engineering and Chemistry, Faculty of Civil Engineering, Czech Technical \\ University in Prague, Thákurova 7, 16629 Prague, Czech Republic \\ * Correspondence: alakatos@eng.unideb.hu; Tel.: +36-3033-468-61
}

Received: 15 January 2020; Accepted: 11 February 2020; Published: 13 February 2020

\begin{abstract}
Nowadays, the usage of thermal insulation materials is widespread not only in the building sector but also in the vehicle industry. The application of fibrous or loose-fill insulation materials like glass wool or mineral wool as well as aerogel is well known. Aerogel-based materials are among the best solid materials for thermal insulation available today; they are prepared through a sol-gel process. For building walls, the glass-fiber-enhanced types are the frequently used ones. They are prepared by adding the liquid-solid solution to the fibrous batting, which is called a sol-gel process. In the present paper, the changes in the most important building physical properties of aerogel blankets after thermal annealing are presented. The samples were subjected to isochronal heat treatments from 70 to $210{ }^{\circ} \mathrm{C}$ for $24 \mathrm{~h}$. The changes in the thermal conductivity were followed by Holometrix Lambda heat flow meter, and differential scanning calorimetry results were also recorded. From the measured values, together with the densities, the most important thermal properties were calculated, such as thermal resistance, diffusivity, effusivity (heat absorption), and thermal inertia. In this paper, we attempt to clarify the role played by thermal annealing in the transient thermal properties of aerogel materials. Besides presenting the measurement results, a theoretical background is given. The investigations of not only the steady-state but also the transient thermal parameters of the materials are momentous at the design stage.
\end{abstract}

Keywords: thermal annealing; aerogel; transient building physical properties

\section{Introduction}

Nowadays, the importance of using thermal insulation materials is well known. The application of thermal insulation materials in order to reduce the energy loss as well as to reduce energy consumption is important both in the building and in the industrial sectors. The commonly used insulation materials are the foamy ones (mainly plastic) with their limited use where higher temperatures can occur, and the fibrous materials where the appearance of moisture causes problems. Furthermore, the use of super insulation materials (SIM), e.g., aerogel and vacuum insulation panels, is also widespread [1-9]. Thermal insulating materials are exposed to different temperatures and humidity environments, where their insulation performance might change. Solid aerogel is an open-cell (porous) material with low density and nano-structured cells. It is prefabricated by supercritical drying of various types of gels, but it is most commonly made from silica gel [10-13]. It is reported by several authors that aerogel is one of the most important super-insulation materials, having a lower thermal conductivity of the air under normal circumstances as well as having lower thermal conductivity than $0.018 \mathrm{~W} /(\mathrm{m} \mathrm{K})$. In the literature, it was presented several times that moisture and humid environments have a significant effect on the thermal insulation capability of this material [14-19]. It was further shown that thermal 
annealing has an effect on both the structure and the chemical composition of the aerogel [20-22]. Thermal annealing can be an adequate method to simulate the passing of the time [20]. It can be thought of as an artificial ageing process of the materials. A further finding of this paper is the conclusion that the physical properties of insulation materials as well as their lasting can be simulated in laboratories within a relatively short time period. Jelle, in another paper [21], also presented a comprehensive comparison of the insulation materials with possible applications. There, it was further emphasized that thermal ageing durability with different climatic exposures executed in laboratories is highly significant. Miros [22] gives an overall presentation about the possible thermal ageing processes executed on mineral wool fibrous batts. He executed measurements from 100 to $600{ }^{\circ} \mathrm{C}$ with $100^{\circ} \mathrm{C}$ steps. Siligardi and colleagues reported that the fiber-reinforced aerogel is a state-of-the-art solution for refurbishing historic buildings [23]. Furthermore, they reported that the investigations of the effects of thermal treatments are very important. Therefore, they treated the sample at high temperatures (up to $1400^{\circ} \mathrm{C}$ ) since the examinations of the transient thermal parameters of the insulation materials are also very important.

Besides thermal conductivity and mass density measurements, specific heat capacity test results gained by differential scanning calorimetry were used for calculating changes in the transient building physical properties of the materials. The changes and results after the heat treatment are highlighted in brief. The influence of the rise in the temperature of the surroundings, as in aging, can be simulated with thermal annealing at unusual temperature ranges. The thermal treatment of the samples for modeling the elapsing time (aging) is usually carried out at around $70^{\circ} \mathrm{C}$. A method for modeling the aging effects of materials can be executed by thermal annealing. In our latest paper [2], we showed that the samples treated at $70{ }^{\circ} \mathrm{C}$ for 6 weeks did not suffer any physical changes. After isothermal heat treatments at $70{ }^{\circ} \mathrm{C}$, the thermal conductivity remained constant. We went further with the experiments and tested the samples at elevated temperatures from 100 to $210^{\circ} \mathrm{C}$ for $24 \mathrm{~h}$. The mentioned temperature ranges can appear in building service systems, pipes transporting hot fluids or steams, which may be combustion products; therefore, they should be insulated. Moreover, they can also happen in industrial or power-generating settings.

The main aims of our paper are the following:

1. Thermal conductivity measurement tests executed on glass-fiber-reinforced aerogel insulation after isochronal $(t=24 \mathrm{~h})$ heat treatments at $70,100,130,150,180$, and $210^{\circ} \mathrm{C}$.

2. Measurement of the change in the mass density of the samples after heat treatments.

3. Differential scanning calorimetry measurements on the sample.

4. From the measured values we calculated the most important transient building physical parameters of the samples, such as (a) diffusivity, (b) effusivity, and (c) inertia. As a result, we concluded the changes due to the heat treatments, and we defined the effective heat capacity.

\section{Materials and Methods}

\subsection{Theory}

The two most important thermal properties belonging to heat transfer are thermal conductivity $(\lambda)$ and thermal diffusivity $(a)$. The definition of thermal conductivity is well known; however, in the understanding of diffusivity, some contradictions might happen.

\section{Thermal Conductivity}

It is well known, that thermal conductivity $\lambda$-usually called lambda or formerly known as the $k$ value of homogenous solid materials — can be characterized easily by the measurement of the steady-state heat flow passing through the material resulted by the $\mathrm{d} T / \mathrm{d} x$ temperature gradient:

$$
q=-\lambda \frac{\mathrm{d} T}{\mathrm{~d} x},
$$


where $q$ is thermal heat flow. With respect to the above equation, it is observable that the movement of the heat is randomized (stochastic). It means that the way of the heat through the material is not linear, but it diffuses through the sample and it suffers collisions [17].

\subsection{Heat Treatments of the Samples}

The thermal annealing of the unpacked probes was executed in the VentiCell 111 equipment (drying oven) at $70,100,130,150,180$, and $210{ }^{\circ} \mathrm{C}$ for $24 \mathrm{~h}$ on the same sample consecutively. With the above equipment, solid samples can be dried at up to $250{ }^{\circ} \mathrm{C}$. It works with hot air circulation using an inbuilt ventilator [5,17]. For measuring the thermal conductivity of the heat-treated samples, the Lambda 2000 heat flow meter (HFM) was used. The measurement order and the equipment are presented in the following papers [5,17]. The thermal conductivities are presented by Lakatos and Trník [1]. For the measurements, glass-fiber-reinforced aerogel was used with the following declared properties (Table 1). The mass densities of the samples were measured with a milligram preciseness balance. The results were used both as input data for the thermal conductivity measurements and for the calculations.

Table 1. The material properties [1].

\begin{tabular}{cc}
\hline$\lambda$ Via Holometrix Apparatus $[\mathbf{W} /(\mathrm{m} \mathrm{K})]$ & 0.017 at $17^{\circ} \mathrm{C}$ \\
\hline$c_{p}[\mathrm{~J} /(\mathbf{k g ~ K})]$ & 1000 at $40{ }^{\circ} \mathrm{C}$ \\
\hline$\rho\left[\mathrm{kg} / \mathrm{m}^{3}\right]$ & 150 \\
\hline
\end{tabular}

\subsection{Differential Scanning Calorimetry Measurements}

The measurement to determine the specific heat capacity $c_{p}$ was executed by differential scanning calorimetry, namely apparatus DSC 822e from Mettler Toledo, together with a Julabo FT 900 cooling device. The temperature interval was from 25 to $300^{\circ} \mathrm{C}$ with a heating rate of $10{ }^{\circ} \mathrm{C} / \mathrm{min}$ and with a $5 \mathrm{~min}$ isothermal regime before and after linear heating. The measurement order was clearly described in $[1,2]$.

\subsection{Calculated Material Properties}

In thermodynamics and building physics, the two most important parameters to evaluate the thermal insulation capability of the materials are the thermal conductivity and the thermal diffusivity. The most significant difference between them is their application. Thermal conductivity is mainly used for steady state cases to reach the overall thermal transmittance of a structure, while diffusivity is used for transient cases, before the steady stage.

\subsubsection{Thermal Diffusivity}

In heat transfer analysis, thermal diffusivity $(a)$ is thermal conductivity $(\lambda)$ divided by density $(\rho)$ and specific heat capacity $\left(c_{p}\right)$ at constant pressure, where the product of the density and the specific heat is known as the effective heat capacity $C_{e f f}$. It measures the rate of transfer of heat in the material from the hot end to the cold end [24].

$$
a=\frac{\lambda}{\rho c_{p}}=\frac{\lambda}{C_{e f f}} .
$$

In a material with high diffusivity, heat passes through quickly due to its thermal bulk. The physical meaning behind thermal diffusivity is associated with the speed of the propagation of heat during the changes in temperature over time [1,24].

$$
\frac{\mathrm{d} T}{\mathrm{~d} t}=a \nabla^{2} T
$$


In another interpretation, thermal diffusivity is the amount that gives the change in temperature closed in a unit volume of the material by the quantity of heat energy that passes through under unit time and a unit area of a layer of unit thickness with a unit temperature difference between its sides. The exact meaning of heat diffusion is the transmission of the temperature difference in the function of time. For instance, in a pure metal sheet (e.g., $\mathrm{Al}, \mathrm{Cu}$ ), having many free electrons, the heat diffuses through faster than in a fibrous insulation blanket such as aerogel [25-27].

\subsubsection{Thermal Effusivity or Heat Absorption}

The second thermal property needed in time-varying problems is thermal effusivity $(e)$ defined as:

$$
e=\sqrt{\rho \lambda c_{p}}=\frac{\lambda}{\sqrt{a}}=\rho c_{p} \sqrt{a}=C_{e f f} \sqrt{a},
$$

Heat absorption can be calculated as the square root of the multiplication of thermal conductivity, density, and specific heat capacity. Thermal effusivity of a material is a measure of its ability to exchange thermal energy with its surroundings [11]. In other words, thermal effusivity is a property of a material for describing the ability of a material for storing and discharging heat. A material having high thermal effusivity provides to be thermally activated quickly; in this context, it allows more thermal load to be stored inside the material.

\subsubsection{Thermal Inertia}

In a sense, thermal diffusivity is the measure of thermal inertia [3]. The thermal inertia of a material is the multiplication of its thermal resistance and heat absorption coefficient (effusivity), where $d$ is the thickness of the sample (in this case $d=0.01 \mathrm{~m}$ ). Thermal inertia is also used in transient cases. In heat transfer and building physics, a higher value means higher resistance or effusivity.

$$
I=R e=\frac{d}{\lambda} e,
$$

\section{Results}

\section{Changes in the Thermal Properties}

The results of the measured thermal conductivities are as follows. In a recent paper it was presented that for the thermal conductivity after heat treatment at $70{ }^{\circ} \mathrm{C}$ a constant value was reached: $0.0171 \pm 0.002 \mathrm{~W} /(\mathrm{m} \mathrm{K})[2]$. For this case, we executed isochronal heat treatments from 70 to $210{ }^{\circ} \mathrm{C}$ for $24 \mathrm{~h}$, and we measured the thermal conductivities. Furthermore, it has to be mentioned that after these isochronal investigations, where the temperature was set at $100,130,150,180$, and $210^{\circ} \mathrm{C}$, significant changes were found both in the thermal conductivity and in the density of the material (see Table 2). The change both in the density and in the thermal conductivity can be identified as the dehydration process of the samples and the crystallization process [28]. It was also stated in Ref. [28]

Table 2. The thermal conductivity, density, and specific heat capacity of the studied aerogel sample [1].

\begin{tabular}{ccccccc}
\hline & $\mathbf{7 0}{ }^{\circ} \mathbf{C}$ & $\mathbf{1 0 0}{ }^{\circ} \mathbf{C}$ & $\mathbf{1 3 0}{ }^{\circ} \mathbf{C}$ & $\mathbf{1 5 0}{ }^{\circ} \mathbf{C}$ & $\mathbf{1 8 0}{ }^{\circ} \mathbf{C}$ & $\mathbf{2 1 0}{ }^{\circ} \mathbf{C}$ \\
\hline$\lambda[\mathbf{W} /(\mathbf{m ~ K})]$ & 0.0171 & 0.0171 & 0.0162 & 0.0181 & 0.0180 & 0.0200 \\
\hline$\rho\left[\mathbf{k g} / \mathbf{m}^{3}\right]$ & 150.17 & 150.24 & 150.24 & 148.68 & 147.96 & 147.48 \\
\hline$c_{p}[\mathbf{J} /(\mathbf{k g ~ K})]$ & 1795 & 1853 & 1962 & 2128 & 2369 & 2656 \\
\hline
\end{tabular}

Thermal conductivities can be found in the function of thermal diffusivities (Figure 1) calculated from the above-mentioned equations, as suggested by Salazar [24]. Salazar [24] highlights the necessity 
to plot thermal conductivity as a function of density. We can observe that due to the heat treatment the diffusivity stayed in the same order of magnitude; however, the specific heat capacity strongly increased.

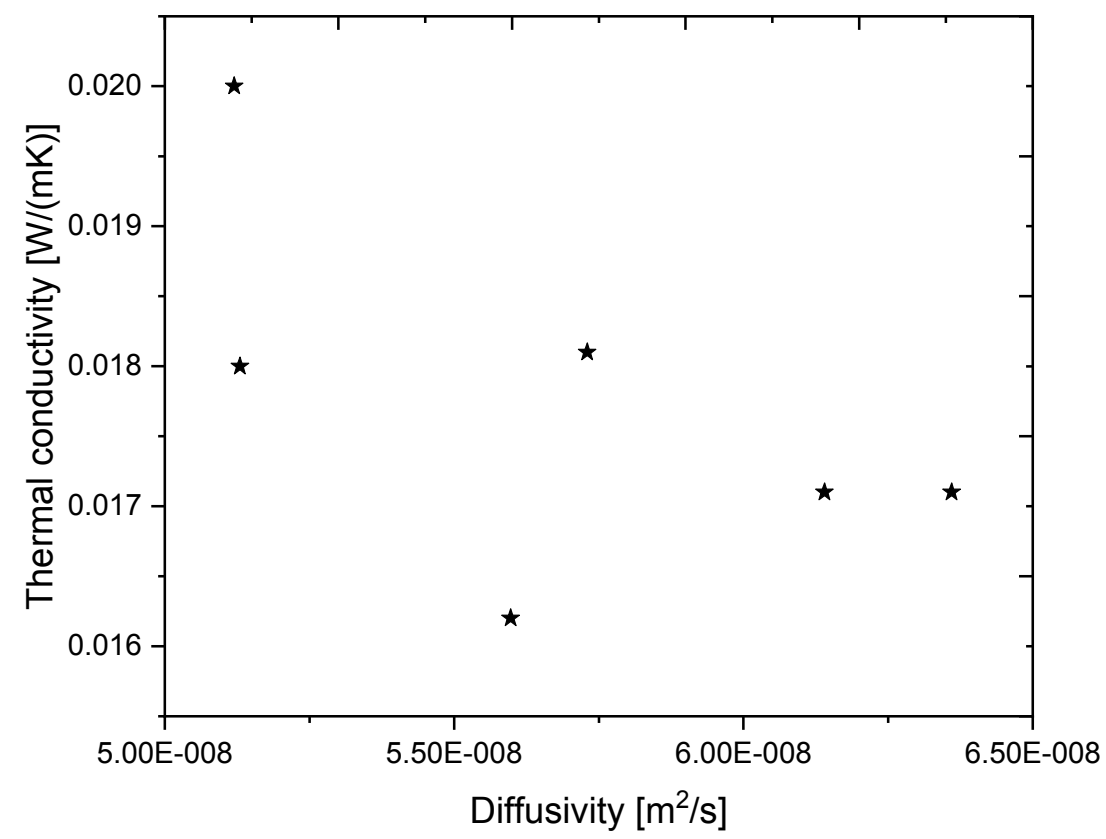

Figure 1. Thermal diffusivity versus thermal conductivity.

In Figure 2, one can see the effects of thermal annealing (temperature) on diffusivity and effusivity (heat absorption).

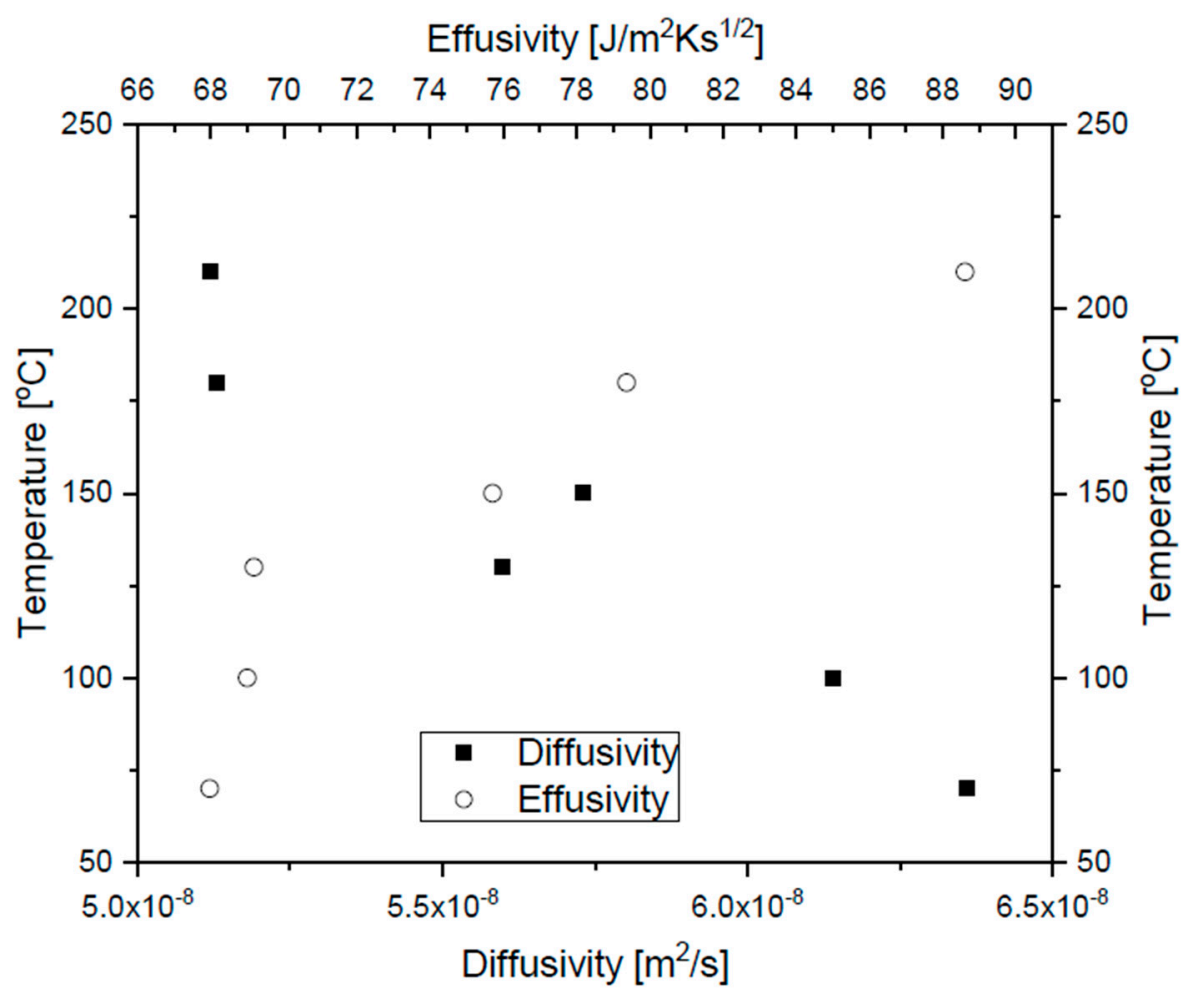

Figure 2. Thermal diffusivity and effusivity versus temperature.

In Figure 2, the role of temperature in the change of thermal diffusivity and effusivity can be found. The results show only a slight change in diffusivity. In another paper, the authors reported 
thermal diffusivity of conventional fibrous insulation materials (mineral or glass wools) to be about $10^{-7} \mathrm{~m}^{2} / \mathrm{s}$. Wei et al. [25] presented diffusivity results on the bio-based insulation materials with a density greater than $300 \mathrm{~kg} / \mathrm{m}^{3}$ and with thermal conductivity of $0.1-0.3 \mathrm{~W} /(\mathrm{m} \mathrm{K})$. In their case, the thermal diffusivities ranged from 1 to $2 \times 10^{-7} \mathrm{~m}^{2} / \mathrm{s}$, evaluated from experimentally characterized $c_{p}$. In order to go deeper into the background of the changes both in the thermal diffusivity and in the thermal effusivity, Figure 2 and Table 2 were created. The changes in the thermal diffusion values are mostly forced by the rapid increase of the $c_{p}$ function. The calculated $10^{-8} \mathrm{~m}^{2} / \mathrm{s}$ value has a good correlation with the above-mentioned ones presented in the literature. From Figure 2, one can conclude increasing thermal effusivity. This is caused by the monotonous increase in the specific heat capacity and the decrease in the density, as well as the increase in the thermal conductivity, for annealing above $150{ }^{\circ} \mathrm{C}$.

The change in the calculated thermal inertia as a function of temperature is presented in Figure 3. One can see that thermal inertia increased with about $20 \%$ after thermal annealing above $200{ }^{\circ} \mathrm{C}$. The graph shows a strong and monotonous increase between 100 and $180^{\circ} \mathrm{C}$. Let us mention that the point belonging to $150{ }^{\circ} \mathrm{C}$ has a deviant behavior caused by a decrease in the density and an increase in the specific heat capacity.

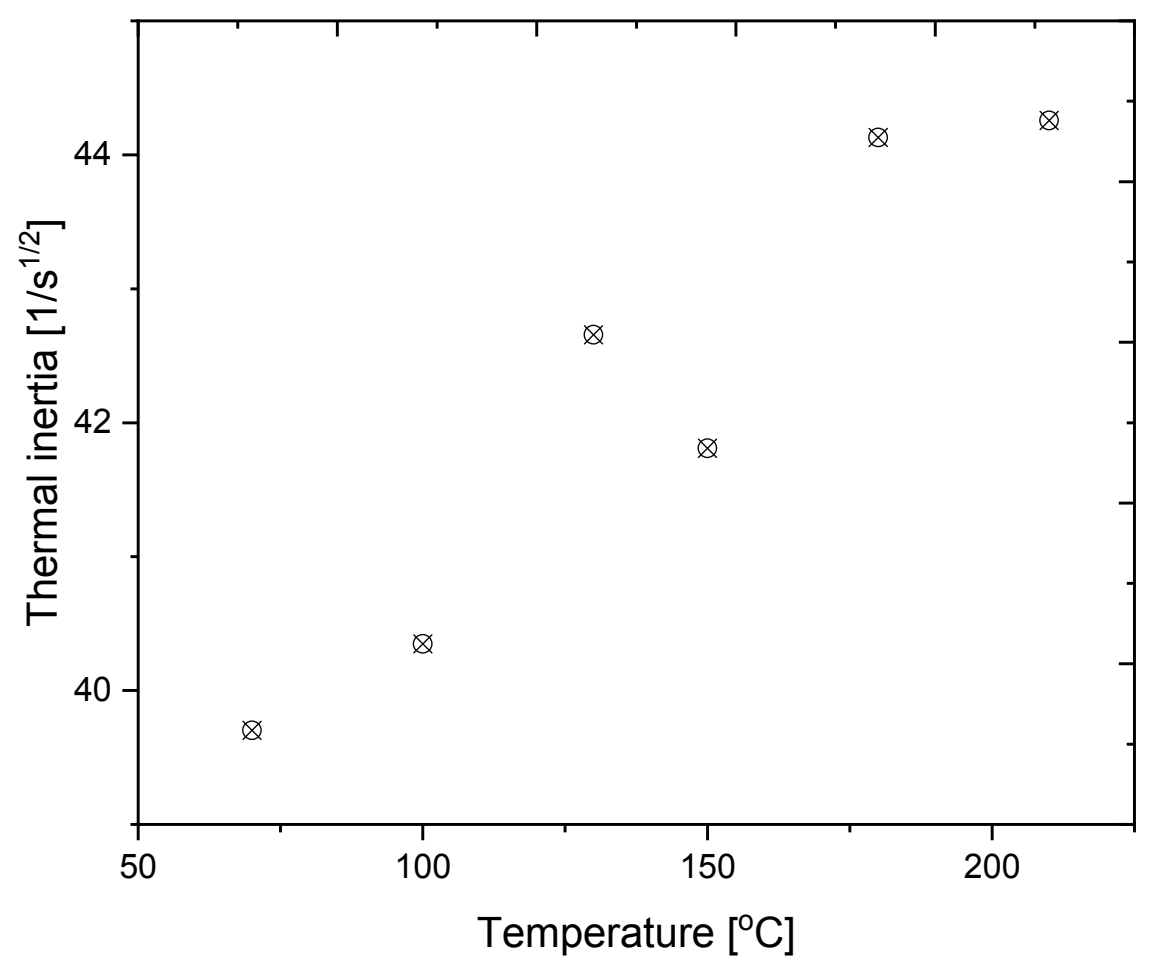

Figure 3. Thermal inertia as a function of temperature.

In order to understand all the above changes, Figure 4 and Table 3 were created.

Table 3. The material test results.

\begin{tabular}{|c|c|}
\hline Microscope $(M=20 \times)$ & growth of $\mathrm{SiO}_{2}$ grains \\
\hline Scanning Electron microscopy $(\mathrm{M}=100 \times)$ & growth of $\mathrm{SiO}_{2}$ grains \\
\hline$X$-ray diffraction $-2 \Theta$ & Twin peaks $22.5-27^{\circ}$, maybe crystallization \\
\hline Raman spectroscopy & $\begin{array}{l}\text { - } \quad \mathrm{SiO}_{2} \text { peak decreases and the } \mathrm{c}-\mathrm{SiO}_{2} \text { appears } \\
\text { and increasing. } \\
\text { - The sign of both the organic groups and the } \mathrm{OH} \\
\text { roots is decreasing }\end{array}$ \\
\hline
\end{tabular}




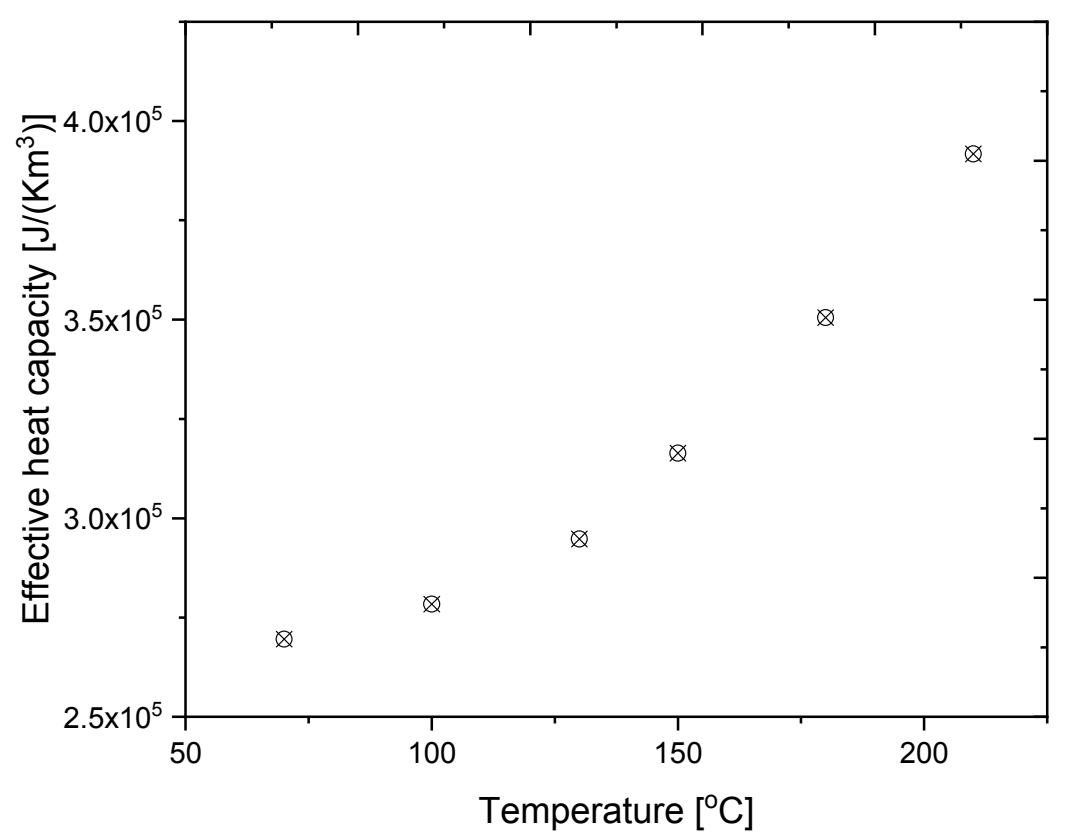

Figure 4. Effective heat capacity in the function of temperature.

The effective heat capacity was calculated using Equation (3), which is the most important thermal parameter of heterogeneous materials. It shows an exponential increase in the function of the temperature presented in Figure 4. The background of this is the rapid increase in the specific heat capacity. Material test results were presented in order to see the causes of the changes in thermal annealing. Moreover, in our previous study [28], both physical (structural) and chemical investigations were executed on the samples (Table 3).

From the material tests, one can conclude that the samples after thermal annealing go through crystallization processes on one hand and grain separation on the other hand. Lakatos and Csarnovics [28] presented that the number and intensity of the $\mathrm{OH}$ roots are decreasing. This means dehydration. Crystallization, grain separation, and dehydration cause the rapid change in the specific heat capacity and a slight decrease in the density. Moreover, the growth of aerogel grains leads to an increase in thermal conductivity. All of these factors together are responsible for the changes in the diffusivity, effusivity, and inertia.

\section{Conclusions}

The current article presents laboratory tests and calculations introduced and carried out on glass-fiber-reinforced aerogel after heat treating. Calculations were executed in order to see the changes in thermal diffusivity, effusivity, and thermal inertia. These calculations were based on measured thermal conductivities, densities, and specific heat capacities after thermal treatments of the samples. Moreover, the role played by thermal diffusivity as the quantity that governs the speed of heat propagation in transient problems, was also analyzed in this study. Furthermore, the relationship between thermal conductivity and thermal diffusivity was explained from a new perspective. From the results, we show that in the isochronal heat-treating case, significant changes were found in the material properties over $150{ }^{\circ} \mathrm{C}$. The varying elevated temperatures might cause unwanted (decreasing) thermal insulation capability. Furthermore, these results were compared with other results in order to understand the changes caused by thermal annealing. It is further shown that the changes in the building's physical parameters are caused by material changes. In reality, the thermal conductivities can be measured by steady-state methods, while the diffusivities can be found through transient methods. The investigations of the thermal performance of materials are very important, for instance, to define the transient thermal behavior of the building materials. The overall thermal 
transmittance (U-value) was calculated for steady-state conditions, but this cannot give exact solutions when the thermal parameters are rapidly changing. For these cases, the exact characterization of the abovementioned transient thermal properties are necessary. Investigations carried out at unusual but not high temperatures (up to $250^{\circ} \mathrm{C}$ ) should also be important for industrial cases. We also showed changes in the effective heat capacity.

Author Contributions: Conceptualization, Á.L.; methodology, Á.L.; and A.T.; investigation, Á.L. and A.T.; writing—original draft preparation, Á.L.; writing—review and editing, Á.L. and A.T.; supervision, Á.L.; funding acquisition, A.L. All authors have read and agreed to the published version of the manuscript.

Funding: This research was funded by the Ministry of Innovation and Technology in Hungary, grant number NKFIH-1150-6/2019.

Acknowledgments: The research was financed by the Higher Education Institutional Excellence Program (NKFIH-1150-6/2019) of the Ministry of Innovation and Technology in Hungary, within the framework of the Energy thematic program of the University of Debrecen.

Conflicts of Interest: The authors declare no conflict of interest. The funders had no role in the design of the study; in the collection, analyses, or interpretation of data; in the writing of the manuscript, or in the decision to publish the results.

\section{References}

1. Lakatos, Á.; Trnik, A. Thermal Characterization of Fibrous Aerogel Blanket, MATEC Web Conf 282, 01001. In Proceedings of the 2019 Central European Symposium on Building Physics 2019 CESBP, Prague, Czech Republic, 2-5 September 2019. [CrossRef]

2. Lakatos, Á.; Csík, A.; Trník, A.; Budai, I. Effects of the Heat Treatment in the Properties of Fibrous Aerogel Thermal Insulation. Energies 2019, 12, 2001. [CrossRef]

3. Iswara, S.; Griffa, M.; Kaufmann, R.; Beltrand, M.; Hubera, L.; Brunner, S.; Lattuad, M.; Koebel, M.M.; Malfait, W.J. Effect of aging on thermal conductivity of fiber-reinforced aerogel composites: An X-ray tomography study. Micr. Mes. Mat. 2019, 278, 289-296. [CrossRef]

4. Ebert, H.P. Thermal Properties of Aerogels. In Aerogels Handbook; Aegerter, A., Leventis, N., Koebel, M., Eds.; Springer: New York, NY, USA, 2011; pp. 537-564. [CrossRef]

5. Lakatos, Á. Stability investigations of the thermal insulating performance of aerogel blanket. Energy Build. 2019, 139, 506-516. [CrossRef]

6. Koebel, M.; Rigacci, A.; Achard, P. Aerogels for Superinsulation: A Synoptic View. In Aerogels Handbook; Aegerter, M.A., Leventis, N., Koebel, M.M., Eds.; Springer: Berlin/Heidelberg, Germany, 2011. [CrossRef]

7. Schultz, J.M.; Jensen, K.I.; Kristiansen, F.H. Super insulating aerogel glazing. Sol. Eneregy Mat. Sol. Cells 2005, 89, 275-285. [CrossRef]

8. Galliano, R.; Ghazi Wakili, K.; Stahl, T.; Binder, B.; Daniotti, B. Performance evaluation of aerogel-based and perlite-based prototyped insulations for internal thermal retrofitting: HMT model validation by monitoring at demo scale. Eneregy Build. 2016, 12, 275-286. [CrossRef]

9. Ghazi Wakili, K.; Stahl, T.; Heiduk, E.; Schuss, M.; Vonbank, R.; Pont, U.; Sustr, C.; Wolosiuk, D.; Mahdavi, D. High Performance Aerogel Containing Plaster for Historic Buildings with Structured Façades. Energy Proc. 2015, 78, 949-954. [CrossRef]

10. Baetens, R.; Jelle, B.P.; Gustavsen, A. Aerogel insulation for building applications: A state-of-the-art review. Energy Build. 2011, 43, 761-769. [CrossRef]

11. Lucchi, E.; Roberti, F.; Alexandra, T. Definition of an experimental procedure with the hot box method for the thermal performance evaluation of inhomogeneous walls. Energy Build. 2018, 179, 99-111. [CrossRef]

12. Berardi, U.; Lakatos, Á. Thermal bridges of metal fasteners for aerogel-enhanced blankets. Energy Build. 2019, 185, 307-315. [CrossRef]

13. Stahl, T.; Brunner, S.; Zimmermann, M.; Ghazi Wakili, K. Thermo-hygric properties of a newly developed aerogel based insulation rendering for both exterior and interior applications. Energy Build. 2012, 44, 114-117. [CrossRef] 
14. Lucchi, E.; Becherini, F.; Di Tuccio, M.C.; Troi, A.; Frick, J.; Roberti, F.; Hermann, C.; Fairnington, I.; Mezzasalma, G.; Pockelé, L.; et al. Thermal performance evaluation and comfort assessment of advanced aerogel as blown-in insulation for historic buildings. Build. Environ. 2017, 122, 258-268. [CrossRef]

15. Lakatos, Á. Moisture induced changes in the building physics parameters of insulation materials. J. Sci. Technol. Built Environ. 2016, 22, 3. [CrossRef]

16. Hoseini, A.; Bahrami, M. Effects of humidity on thermal performance of aerogel insulation blankets. J. Build. Eng. 2017, 13, 107-115.

17. Lakatos, Á. Investigation of the moisture induced degradation of the thermal properties of aerogel blankets: Measurements, calculations, simulations. Energy Build. 2017, 139, 506-516. [CrossRef]

18. Koci, V.; Madera, J.; Jerman, M.; Trnik, A.; Cerny, R. Determination of the equivalent thermal conductivity of complex material systems with large-scale heterogeneities. Int. J. Therm. Sci. 2014, 86, 365-373. [CrossRef]

19. Lakatos, Á.; Deák, I.; Berardi, U. Thermal characterization of different graphite polystyrene. Int. Rev. App. Sci. Eng. 2018, 9, 163-168. [CrossRef]

20. Jelle, B.P. Accelerated climate ageing of building materials, components and structures in the laboratory. J. Mat. Sci. 2012, 47, 6475-6496. [CrossRef]

21. Jelle, B.P. Traditional, state-of-the-art and future thermal building insulation materials and solutions-properties, requirements and possibilities. Energy Build. 2011, 43, 2549-2563. [CrossRef]

22. Miros, A. Thermal Aging Effect on Thermal Conductivity Properties of Mineral Wool Pipe Samples at High Temperature. In Proceedings of the 3rd World Congress on Mechanical, Chemical, and Material Engineering (MCM'17), Rome, Italy, 8-10 June 2017. Paper No. HTFF 172. [CrossRef]

23. Siligardi, C.; Miselli, P.; Francia, E.; Gualtieri, M.L. Temperature-induced microstructural changes of fiber-reinforced silica aerogel (FRAB) and rock wool thermal insulation materials: A comparative study. Energy Build. 2017, 138, 80-87. [CrossRef]

24. Salazar, A. On thermal diffusivity. Eur. J. Phys. 2003, 24, 351-358. [CrossRef]

25. Wei, G.; Zhang, X.; Yu, F.; Chen, K. Thermal diffusivity measurements on insulation materials with the laser flash method. Int. J. Thermophys. 2006, 27, 235-243. [CrossRef]

26. Boulaoued, I.; Amara, I.; Mhimid, A. Experimental determination of thermal conductivity and diffusivity of new building insulating materials. Int. J. Heat Techn. 2016, 34, 325-331. [CrossRef]

27. Lamrani, M.; Laaroussi, N.; Khabbazi, A.; Khalfaoui, M.; Garoum, M.; Feiz, A. Experimental study of thermal properties of a new ecological building material based on peanut shells and plaster. Case Stud. Const. Mat. 2017, 7, 294-304. [CrossRef]

28. Lakatos, Á.; Csarnovics, I. Influence of thermal annealing on structural properties of silica aerogel super insulation material. J. Thermal. Anal. Calorim. 2019, 1-9. [CrossRef] 